\title{
Familial correlations and inter-relationships of four asthma-associated quantitative phenotypes in 320 French EGEA families ascertained through asthmatic probands
}

\author{
Emmanuelle Bouzigon ${ }^{\star 1}$, Valérie Chaudru ${ }^{1}$, Anne-Sophie Carpentier ${ }^{1}$, \\ Marie-Hélène Dizier ${ }^{2}$, Marie-Pierre Oryszczyn ${ }^{3}$, Jean Maccario ${ }^{3}$, Francine Kauffmann ${ }^{3}$ \\ and Florence Demenais ${ }^{1}$ \\ ${ }^{1}$ INSERM-Université d'Evry EMIO006, Evry, France; ${ }^{2}$ INSERM U535, Villejuif, France; ${ }^{3}$ INSERM U472, Villejuif,
France
}

Asthma is a complex disease, associated with biological and physiological phenotypes including immunoglobulin E (IgE) levels, sum of positive skin prick tests to allergens (SPTQ), eosinophil counts (EOS) and percent predicted forced expiratory volume in $1 \mathrm{~s}\left(\% \mathrm{FEV}_{1}\right)$. We investigated the patterns of familial correlations and the inter-relationships of these four quantitative phenotypes, using the general class $D$ regressive model, in 320 French EGEA nuclear families ascertained through 204 offspring (set $A$ ) and 116 parents (set B). Familial correlations of IgE and SPTQ were consistent with a model including no spouse correlation and equal parent-offspring and sib-sib correlations $\left(\rho_{\mathrm{PO}}=\rho_{\mathrm{SS}}=0.25\right.$ for $\operatorname{lgE}$ and 0.15 for SPTQ), this model being compatible with an additive polygenic model in the whole sample and the two

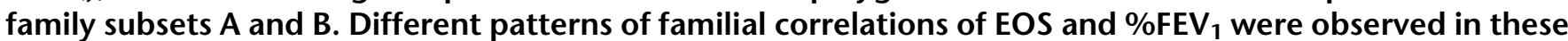
two sets. In set $A$, the best fitting model included no spouse correlation and equality of parent-offspring and sib-sib correlations $\left(\rho_{\mathrm{PO}}=\rho_{\mathrm{SS}}=0.14\right.$ for EOS and 0.23 for $\left.\% F E V_{1}\right)$. In set B, EOS had only a significant $\rho_{\mathrm{SS}}$ of 0.28 , while $\% \mathrm{FEV}_{1}$ had significant $\rho_{\mathrm{MO}}$ of 0.28 and $\rho_{\mathrm{SS}}$ of 0.16 . Analysis of shared familial determinants between these phenotypes indicated an overlap of at most $30 \%$ in $\rho_{\mathrm{FO}}$ for IgE and SPTQ and in both $\rho_{\mathrm{FO}}$ and $\rho_{\mathrm{MO}}$ for IgE and EOS, while determinants of \%FEV ${ }_{1}$ and atopy-related phenotypes appear distinct. These results may have implications for further linkage and association studies with genetic markers.

European Journal of Human Genetics (2004) 12, 955-963. doi:10.1038/sj.ejhg.5201241

Published online 7 July 2004

Keywords: asthma; atopy; lung function; familial correlations; regressive model

\section{Introduction}

Asthma is a complex and heterogeneous disorder, which is associated with biological and physiological phenotypes,

*Correspondence: Dr E Bouzigon, INSERM-Université d'Evry EMI0006, Tour Evry 2 - Génopole, 523, Place des Terrasses de l'Agora, 91034 Evry Cedex, France. Tel: + 331608738 20; Fax: + 331608738 48; E-mail: bouzigon@evry.inserm.fr

Received 24 December 2003; revised 15 April 2004; accepted 7 May 2004 those related to allergy and inflammation (total serum immunoglobulin E levels (IgE), specific IgE and skin test reactivity to common aero-allergens and eosinophilia) and those related to lung function (forced expiratory volume in $1 \mathrm{~s}\left(\mathrm{FEV}_{1}\right)$, forced vital capacity and airway responsiveness).

A close correlation between asthma and the atopic status (high IgE levels, positive skin test responses to allergens) has long been established (see Burrows et al ${ }^{1}$ and Postma 
et $a l^{2}$ for a review). However, atopy is not specific to asthma. High blood eosinophil counts are known to be related to asthma. ${ }^{3-5}$ Spirometric measures as $\mathrm{FEV}_{1}$ are closely but not specifically associated with asthma and atopy. There have been conflicting reports on the relationship between atopy and lung function. ${ }^{6-9}$ Inflammation of the airways in asthma is characterized by an eosinophilic infiltrate in the bronchial mucosa and $\mathrm{FEV}_{1}$ is inversely related to eosinophils. ${ }^{10-13}$

Genetic factors play a substantial role in the pathogenesis of asthma. Considerable efforts are currently being made in the detection of genetic loci underlying asthma and asthma-associated phenotypes (see Cookson ${ }^{14}$ for a review). A better knowledge of the relationships among phenotypes associated with a complex disease, such as asthma, may help in disentangling the underlying mechanisms by providing guidance in the choice of biological systems and candidate genetic determinants to be studied which may be either common or specific to these phenotypes. Recent studies have shown that multivariate analyses of correlated quantitative phenotypes can enhance the power of mapping quantitative-trait loci with pleiotropic effects. ${ }^{15,16}$ The existence of potential common genetic and/or environmental factors underlying asthmarelated phenotypes has been scarcely investigated. To our knowledge, only one study, in Australian families selected at random from the population, has examined the sharing of genetic determinants by asthma-associated quantitative phenotypes using variance component models and segregation analysis. ${ }^{17,18}$

To provide guidance for further linkage and association studies with genetic markers and thus facilitate the identification of asthma-genes, we examined the patterns of familial correlations and inter-relationships of four asthma-associated quantitative phenotypes (total serum IgE level, a quantitative score of skin prick tests, blood eosinophil counts and $\mathrm{FEV}_{1}$ ), which have not been yet considered together, in 320 French nuclear families ascertained through one asthmatic proband (parent or offspring) using the regressive models. ${ }^{19}$ These models, which describe family patterns of dependence in terms of correlations without introducing a particular scheme of causal relationships, have been shown to be more general than variance component models that specify a causal structure to account for the observed familial correlations and thus impose constraints among these correlations. ${ }^{20}$

\section{Methods}

\section{Study population}

Subjects were enrolled between 1991 and 1995 in the EGEA study, a French epidemiological survey on the environmental and genetic factors of asthma, bronchial hyperresponsiveness and atopy (see Kauffman et al ${ }^{21,22}$ for details). Written informed consent was obtained from all family members participating to the study under an Institutional Review Board-approved protocol. Briefly, a total of 348 nuclear families were recruited through 348 asthmatic probands, aged 7-65 years, followed in chest clinics of five French cities. The inclusion criteria for asthma have been described in details previously. ${ }^{21}$ After exclusion of 28 families for insufficient family information and/or missing data for the analyzed phenotypes, the analyzed sample comprised 320 families (total of 1289 individuals) including 204 families ascertained through 204 asthmatic offspring (133 pediatric ( $<16$ years of age) and 71 adult cases $(\geqslant 16$ years of age)) with their siblings and parents (set A) and 116 families ascertained through 116 asthmatic parents with their spouses and offspring (set B).

\section{Data collected}

Subjects answered a detailed questionnaire on upper and lower airway symptoms, allergic symptoms, medical history and environmental factors. ${ }^{21}$ Environmental factors included mainly active and passive smoking, exposures to indoor and outdoor allergens and occupational exposures. Biological and physiological tests were performed on each participant.

Four traits were considered by the present study: IgE, skin tests to allergens, eosinophil counts (EOS) and percent predicted $\mathrm{FEV}_{1}\left(\% \mathrm{FEV}_{1}\right)$. Total serum IgE levels were measured by radioimmunoassay (Phadebas PRIST technique; Pharmacia diagnostics, AB, France) in one central laboratory (Pasteur Institute, Lyon). Skin prick tests were performed with respect to 11 allergens (including moulds, indoors and outdoors allergens). A positive response was defined as a wheal size minus the negative control being $\geqslant 3 \mathrm{~mm}$. A quantitative score (SPTQ) was constructed as being the number of positive test results. This score was shown to have valid biometric properties. ${ }^{23}$ Total eosinophil count was performed using standard procedures. Spirometric measures were carried out for all subjects above 7 years of age according to the European Respiratory Health Survey protocol. ${ }^{24}$ The best of three $\mathrm{FEV}_{1}$ measures was used to calculate a percentage of predicted $\mathrm{FEV}_{1}$ values $\left(\% \mathrm{FEV}_{1}\right)$ based on age, height and gender. ${ }^{25,26}$

\section{Statistical analysis}

A $\log _{10}$-transformation was used to render total serum $\operatorname{IgE}$ levels and eosinophil counts distributions approximately Normal. SPTQ and \% predicted $\mathrm{FEV}_{1}$ were analyzed in their raw form.

Prior to the familial analysis, each phenotype was adjusted for relevant covariates including age (taken as a continuous variable), gender and smoking habits (divided into three classes: current smokers, ex-smokers and never smokers) using multiple regression. Linear, quadratic and cubic effects of age as well as interactions between covariates were considered. As all probands were asthmatics and asthma is known to be associated with the 
analyzed phenotypes, an indicator variable specifying the position of individuals in the family (probands, probands' blood relatives (parents, offspring or sibs) or unrelated spouses) was included in the regression model. This strategy was shown to correct adequately for the ascertainment of families through asthmatics in a previous segregation analysis of IgE levels. ${ }^{27}$ Moreover, these regression models were built separately in three groups of family members (parents, pediatric offspring $<16$ years of age, adult offspring $\geqslant 16$ years of age), provided the effects of age and sex on the phenotypes analyzed may vary in adults and children. ${ }^{28}$ Each phenotype was adjusted for the significant position and covariates effects and standardized within each group of subjects. All computations were done with the SAS package 8.2.

Analysis of familial correlations of each adjusted phenotype was performed using the Class D regressive model, ${ }^{19}$ which allows to construct various patterns of familial correlations of any origin (genetic and/or environmental). Briefly, the vector of observed quantitative phenotypes for a family is assumed to follow a multivariate normal distribution with an overall mean (assumed equal for all family members, the phenotypes being adjusted prior to analysis) and covariance matrix expressed in terms of the phenotypic variance (assumed equal for all family members, the phenotypes being standardized prior to analysis) and four phenotypic correlations: $\rho_{\mathrm{FM}}$ (between spouse), $\rho_{\mathrm{FO}}$ (between father and offspring), $\rho_{\mathrm{MO}}$ (between mother and offspring) and $\rho_{\mathrm{SS}}$ (between siblings). This class D regressive model that describes family patterns of dependence in terms of correlations without introducing a particular scheme of causal relationships is more general than variance component models that specify a causal structure to account for the observed familial correlations and thus impose constraints among these correlations according to the assumed underlying model. ${ }^{20}$ Moreover, the class $\mathrm{D}$ model permits to distinguish between fatheroffspring and mother-offspring correlations, while these correlations are generally assumed to be equal under variance component models.

Parameter estimations and tests of models were carried out using maximum likelihood methods, as implemented in the REGRESS program. ${ }^{29,30}$ Presence of familial aggregation was first assessed by comparing a model with no familial correlation to a model where all four correlations were estimated. Evidence for each familial correlation was tested by comparing a model including all correlations except for the one tested being set to zero to a general model including all of them. Specific patterns of correlations were then tested including a model specifying equal father-offspring and mother-offspring correlations $\left(\rho_{\mathrm{FO}}=\rho_{\mathrm{MO}}=\rho_{\mathrm{PO}}\right)$ and a model specifying equal parentoffspring $\left(\rho_{\mathrm{PO}}\right)$ and sib-sib correlations $\left(\rho_{\mathrm{PO}}=\rho_{\mathrm{SS}}\right)$ against a model where these parameters were freely estimated. A regressive model, which constraints $\rho_{\mathrm{PO}}$ and $\rho_{\mathrm{SS}}$ to be equal, is equivalent to a pure polygenic model due to additive genetic effects with heritability $H=2 \rho_{\mathrm{PO}}=2 \rho_{\mathrm{SS} .}{ }^{20}$ An excess of $\rho_{\text {SS }}$ with respect to $\rho_{\text {PO }}$ can be interpreted in terms of dominance effects and/or sibling common environment. Homogeneity of the familial correlation estimates between the two family sets A and B was also tested. ${ }^{31}$

In order to investigate whether familial determinants are shared between phenotypes, each phenotype of interest (eg, total IgE) was adjusted alternatively for each of the three other phenotypes by adding this phenotype (eg, SPTQ, EOS or $\% \mathrm{FEV}_{1}$ ) in the multiple regression model prior to familial analysis. Estimates of familial correlations of a phenotype adjusted for covariates and another phenotype were compared to those of this same phenotype only adjusted for covariates (baseline phenotype). A reduction in the magnitude of these familial correlations suggests sharing of familial determinants (genetic and/or environmental). To assess the magnitude of any change in the estimates of familial correlations, we used an approach based upon profile likelihoods. ${ }^{17,32}$ For example, if a reduction in a given familial correlation was observed, the maximum likelihood of the unconstrained model with all parameters estimated was compared to the maximum likelihood of the constrained model by fixing that correlation to the value previously obtained with the baseline phenotype (only adjusted for covariates) and estimating all other parameters. The ratio of these maximum likelihoods measures the plausibility of the hypothesis that the true value of the correlation was unchanged by adjusting the phenotype of interest for another one. In standard likelihood ratio tests of nested models, a likelihood ratio of 6.8 corresponds to a significance $P$-value of 0.05 . This strategy was chosen to make comparisons with a similar analysis of asthma quantitative phenotypes in Australian families. ${ }^{17}$

\section{Results}

\section{Characteristics of families}

The main characteristics of families sets A and B are shown in Table 1. Among the first-degree relatives of the probands, the proportions of asthmatics among the probands' parents from set A (19.7\%) and the probands' offspring from set B (18.7\%) were similar and both lower than this proportion among probands' siblings from set A (29.0\%) $(P<0.001)$. Only $2.8 \%$ of probands' spouses were asthmatics.

\section{Effects of family position, age, gender and smoking habits}

The family position variable was found to be highly associated with IgE, EOS, SPTQ and $\mathrm{FFEV}_{1}(P<0.0001$ for each trait in each group of subjects, except that $P=0.05$ for $\% \mathrm{FEV}_{1}$ in offspring $<16$ years), reflecting the strong association of each phenotype with asthma. When includ- 
Table 1 Characteristics of family members in each of the two sets of families: set A ascertained through asthmatic offspring and set $\mathrm{B}$ ascertained through asthmatic parents

\begin{tabular}{|c|c|c|c|c|c|c|}
\hline & \multicolumn{3}{|c|}{ Set $B$ (836 subjects) } & \multicolumn{3}{|c|}{ Set $B$ (415 subjects) } \\
\hline & \multirow{2}{*}{$\begin{array}{l}\text { Parents } \\
(\mathrm{n}=380)\end{array}$} & \multicolumn{2}{|c|}{ Offspring } & \multicolumn{2}{|c|}{ Parents } & \multirow{2}{*}{$\begin{array}{l}\text { Offspring } \\
(\mathrm{n}=193)\end{array}$} \\
\hline & & $\begin{array}{l}\text { Probands } \\
(\mathrm{n}=204)\end{array}$ & $\begin{array}{c}\text { Sibs } \\
(\mathrm{n}=252)\end{array}$ & $\begin{array}{l}\text { Probands } \\
(\mathrm{n}=116)\end{array}$ & $\begin{array}{l}\text { Spouses } \\
(\mathrm{n}=106)\end{array}$ & \\
\hline Sex, male (\%) & $189(49.7)$ & $123(60.3)$ & $125(49.6)$ & $62(53.4)$ & $50(47.2)$ & $95(49.2)$ \\
\hline $\operatorname{Age}^{\mathrm{a}}$ (years) & $44.9(7.5)$ & $15.6(7.2)$ & $16.5(7.3)$ & $47.5(9.3)$ & $48.0(8.5)$ & $20.1(8.1)$ \\
\hline Asthma, $n(\%)$ & $75(19.7)$ & $204(100.0)$ & $73(29.0)$ & $116(100.0)$ & $3(2.8)$ & $36(18.7)$ \\
\hline Age at onset ${ }^{a}$ & $16.7(14.6)$ & $6.9(6.2)$ & $6.1(5.4)$ & $27.8(15.8)$ & $33.7(11.7)$ & $9.1(7.0)$ \\
\hline \multicolumn{7}{|c|}{ Smoking habits ${ }^{\mathrm{b}}, n(\%)$} \\
\hline Never smokers & $162(42.6)$ & $43(21.1)$ & $72(28.6)$ & $47(40.5)$ & $53(50.0)$ & $64(33.2)$ \\
\hline Current smokers & $98(25.8)$ & $17(8.3)$ & $32(12.7)$ & $17(14.7)$ & $27(25.5)$ & $45(23.3)$ \\
\hline Ex-smokers & $120(31.6)$ & $11(5.4)$ & $7(2.8)$ & $51(44.0)$ & $26(24.5)$ & $16(8.3)$ \\
\hline Atopy, $n(\%)^{\mathrm{c}}$ & 163 (42.9) & 181 (88.7) & $153(60.7)$ & $67(57.8)$ & $18(17.0)$ & $85(44.0)$ \\
\hline $\log \lg \mathrm{E}^{\mathrm{a}}$ & $1.72(0.72)$ & $2.56(0.53)$ & $2.02(0.71)$ & $2.16(0.63)$ & $1.52(0.70)$ & $1.88(0.70)$ \\
\hline SPTQ ${ }^{\mathrm{a}}$ & $0.9(1.4)$ & $2.3(1.5)$ & $1.3(1.6)$ & $1.4(1.7)$ & $0.3(0.9)$ & $1.1(1.7)$ \\
\hline $\log _{E O S}^{a}$ & $2.16(0.30)$ & $2.57(0.32)$ & $2.34(0.37)$ & $2.34(0.39)$ & $2.11(0.33)$ & $2.24(0.37)$ \\
\hline$\% \mathrm{FEV}_{1}^{\mathrm{a}}$ & $105.6(16.0)$ & $93.0(14.0)$ & $98.4(12.1)$ & $81.6(21.6)$ & $105.4(14.3)$ & $99.1(12.2)$ \\
\hline
\end{tabular}

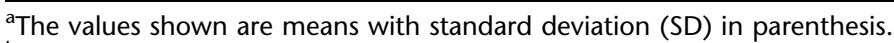

${ }^{\mathrm{b}}$ The smoking variable was not recorded for subjects younger than 16 years of age.

${ }^{\mathrm{c}}$ Atopy was defined as a positive skin prick test to at least one of 11 allergens tested.

ing this position variable in the regression model, the joint age, gender, age* gender and smoking effect on IgE levels was significant in parents and offspring $\geqslant 16$ years of age $(P<0.001)$, while no significant age and gender effect was found in offspring $<16$ years. Eosinophil counts were significantly associated with age and gender in offspring $<16$ years $(P \leqslant 0.02)$. SPTQ was not associated with age, sex or smoking in either group. Smoking had a significant effect on $\% \mathrm{FEV}_{1}$ in parents $(P=0.006)$.

Patterns of familial correlations for each phenotype Estimates of familial correlations for IgE, SPTQ, EOS and $\% \mathrm{FEV}_{1}$, adjusted for family position and significant covariates, are shown in Table 2 for the whole sample and each family set. There was globally strong evidence for familial correlations for each phenotype $(P<0.0001)$ in the whole sample and each family set. For IgE levels, the spouse correlation did not differ significantly from zero $(P=0.60)$ and each of the three other correlations was highly significant $(P<0.001)$. Tests of equality of these correlations indicated a good fit of a model with equal parent-offspring and sib-sib correlations being estimated at 0.25. Similar patterns of correlations were obtained in sets A and B with similar parameter estimates. Similar conclusions were obtained for SPTQ in the whole sample with the best fitting model including no spouse correlation and equal parent-offspring and sib-sib correlations with a point estimate of 0.15 . The same model was also fitting in sets A and B. Test of homogeneity of parameter estimates between these two sets was not significant, but the correlations were lower in set $\mathrm{A}\left(\rho_{\mathrm{PO}}=\rho_{\mathrm{SS}}=0.12 \pm 0.03\right)$ than in set $\mathrm{B}\left(\rho_{\mathrm{PO}}=\rho_{\mathrm{SS}}=0.20 \pm 0.04\right)$. For EOS, the best fitting model in the whole sample included a significant spouse correlation estimated at $0.13(P=0.04)$ and parentoffspring and sib-sib correlations both equal to 0.15 . Although the test of homogeneity of familial correlations between sets A and B was not significant, the best fitting models in each set differed: in set A, this model included no spouse correlation and parent-offspring and sib-sib correlations equal to 0.14 , while in set $\mathrm{B}$, the sib-sib correlation alone was significant $\left(\rho_{\mathrm{SS}}=0.28 \pm 0.10\right.$, $P<0.01)$. For $\% \mathrm{FEV}_{1}$, the best fitting model in the whole sample included no spouse correlation with all other correlations being equal to 0.22 . Again, although the test of homogeneity between the two subsets was not significant, each set led to different conclusions: in set A, the best fitting model was similar to the one found in the whole sample $\left(\rho_{\mathrm{FM}}=0, \rho_{\mathrm{PO}}=\rho_{\mathrm{SS}}=0.23 \pm 0.03\right)$, while in set $\mathrm{B}$, the best fitting model included significant mother-offspring and sib-sib correlations $\left(\rho_{\mathrm{MO}}=0.28 \pm 0.07, P<0.001\right.$ and $\left.\rho_{\mathrm{SS}}=0.16 \pm 0.09, P=0.04\right)$.

\section{Interrelationships between phenotypes}

Associations between phenotypes were first assessed in each of the three groups of family members (parents, offspring $\geqslant 16$ years, offspring $<16$ years) by regressing each phenotype on each other alternatively while including the family position and significant covariates in the model. IgE and SPTQ were significantly and similarly associated in each group: the proportion of variance of $\operatorname{IgE}$ levels accounted for by SPTQ was close to $11 \%(P<0.0001)$, while that of SPTQ explained by IgE was $12 \%(P<0.0001)$. Total IgE and EOS were highly associated with each other in offspring $<16$ years $(23 \%$ of variance of either IgE or EOS explained by the other, $P<0.0001)$. This association was lower in parents ( $5 \%$ of variance, $P<0.0001)$ and in 
Table 2 Maximum likelihood estimates of familial correlations for total IgE levels, sum of positive skin prick tests to allergens (SPTQ), eosinophil counts (EOS) and \%FEV 1 using the class D regressive model

\begin{tabular}{|c|c|c|c|c|c|}
\hline & $\rho_{F M}(S D)^{b}$ & $\rho_{F O}(S D)^{b}$ & $\rho_{M O}(S D)^{b}$ & $\rho_{S S}(S D)^{b}$ & $-2 \ln L^{c}$ \\
\hline \multicolumn{6}{|l|}{ Total IgE } \\
\hline Total sample & $0.03(0.06)$ & $0.22(0.05)$ & $0.29(0.04)$ & $0.29(0.05)$ & 1112.5 \\
\hline Family set A & $0.04(0.07)$ & $0.21(0.05)$ & $0.30(0.05)$ & $0.29(0.06)$ & 747.5 \\
\hline Family set $B$ & $0.02(0.10)$ & $0.24(0.08)$ & $0.26(0.08)$ & $0.31(0.09)$ & 364.7 \\
\hline \multicolumn{6}{|l|}{ SPTQ } \\
\hline Total sample & $0.08(0.06)$ & $0.15(0.04)$ & $0.15(0.04)$ & $0.20(0.05)$ & 1171.1 \\
\hline Family set A & $0.08(0.07)$ & $0.12(0.05)$ & $0.11(0.05)$ & $0.15(0.06)$ & 795.8 \\
\hline Family set B & $0.09(0.11)$ & $0.19(0.07)$ & $0.22(0.08)$ & $0.36(0.09)$ & 370.8 \\
\hline \multicolumn{6}{|l|}{ EOS } \\
\hline Total sample & $0.12(0.06)$ & $0.13(0.04)$ & $0.14(0.04)$ & $0.21(0.05)$ & 1160.8 \\
\hline Family set $A$ & $0.09(0.07)$ & $0.13(0.05)$ & $0.15(0.05)$ & $0.20(0.06)$ & 785.2 \\
\hline Family set B & $0.19(0.10)$ & $0.12(0.08)$ & $0.11(0.08)$ & $0.28(0.11)$ & 374.0 \\
\hline \multicolumn{6}{|l|}{$\% F E V_{1}$} \\
\hline Total sample & $0.02(0.06)$ & $0.19(0.04)$ & $0.27(0.04)$ & $0.23(0.05)$ & 1128.3 \\
\hline Family set A & $0.05(0.07)$ & $0.21(0.05)$ & $0.26(0.05)$ & $0.26(0.06)$ & 754.2 \\
\hline Families set B & $-0.06(0.10)$ & $0.15(0.08)$ & $0.28(0.07)$ & $0.16(0.09)$ & 372.1 \\
\hline
\end{tabular}

${ }^{a}$ Each phenotype was adjusted for the family position of family members with respect to the asthmatic probands and for relevant covariates (age, sex, and/or smoking habits). A logarithmic transformation was taken for IgE and eosinophils.

${ }^{\mathrm{b}} \rho_{\mathrm{FM}}$ : spouse correlation, $\rho_{\mathrm{FO}}$ : father-offspring correlation, $\rho_{\mathrm{MO}}$ : mother-offspring correlation, $\rho_{\mathrm{SS}}:$ sib-sib correlation with standard deviation (SD) in parenthesis. The two other parameters of the models, overall mean and variance, were always close to zero and one (not shown), provided the phenotypes were standardized prior the analysis.

'In $L$ : natural logarithm of the maximum likelihood.

offspring $\geqslant 16$ years $(3 \%$ of variance, $P<0.01)$. The association between SPTQ and EOS and reciprocally was only significant in parents $(P<0.01)$ and offspring $\geqslant 16$ years $(P<0.05)$, the proportion of variance of either SPTQ accounted for by EOS and conversely being, respectively, 7 and $4 \%$ in each group. The $\% \mathrm{FEV}_{1}$ phenotype was associated with EOS and reciprocally in parents $(P=0.02)$ and in offspring $\geqslant 16$ years $(P=0.04)$, the proportion of variance of either phenotype explained by the other being $1 \%$ in each group. No significant association was detected between $\% \mathrm{FEV}_{1}$ and IgE or SPTQ.

Table 3 presents the estimates of familial correlations of each phenotype adjusted for each of the other significantly associated phenotypes as well as the percent reduction of these correlations with respect to the estimates obtained from the corresponding baseline phenotype (results are only shown if a percent reduction of at least 10\% in any previously significant correlation was observed). Adjusting total IgE levels for SPTQ resulted in $18.2 \%$ reduction in the father-offspring correlation $\left(\rho_{\mathrm{FO}}\right)$ in the whole sample. This was associated with a profile likelihood ratio (PLR) of 1.4, consistent with little change in $\rho_{\text {FO }}$. Similar results were obtained in the two subsets, the percent reduction in $\rho_{\mathrm{FO}}$ being greater in set B $(25 \%)$ than in set A $(9.5 \%)$. A similar fall in $\rho_{\mathrm{FO}}$ was observed when adjusting total IgE for EOS: $18.2 \%$ in the whole sample $(P L R=1.5)$ and $28.6 \%$ in set A (PLR $=1.7)$, the reduction in $\rho_{\mathrm{MO}}$ being at most $10 \%$. Adjusting SPTQ for total IgE led to a fall in $\rho_{\mathrm{FO}}$ in the whole sample $(20 \%$ fall, PLR $=1.3)$ and in set A $(16.7 \%$ fall, $\operatorname{PLR}=1.1$ ), while in set $\mathrm{B}$, there was a reduction in both $\rho_{\mathrm{FO}}$ $(15.8 \%$ fall, PLR $=1.1)$ and $\rho_{\mathrm{MO}}(18.2 \%$ fall, PLR $=1.1)$. The results for eosinophils are shown separately in sets A and B, since different patterns of correlations were observed in each set. Adjusting eosinophil counts for total IgE levels led to a $30.8 \%$ fall in $\rho_{\mathrm{FO}}(\mathrm{PLR}=1.5)$ and $26.7 \%$ fall in $\rho_{\mathrm{MO}}$ $(\mathrm{PLR}=1.3)$ in set $\mathrm{A}$. All other analyses led to reduction in familial correlations that were less than $10 \%$.

\section{Discussion}

Our study was designed to include nuclear families ascertained through asthmatic probands aged 7-65 years in order to identify the genetic and environmental determinants of asthma and to characterize possible etiologic heterogeneity. The four asthma-related phenotypes investigated in the present study (IgE, SPTQ, EOS, $\% \mathrm{FEV}_{1}$ ) displayed strong familial correlations with heterogeneity of the patterns of correlations according to the mode of ascertainment of the families (through asthmatic offspring or through asthmatic parents) for two phenotypes (SPTQ and \%FEV ${ }_{1}$ ).

The strong association of IgE, SPTQ, EOS and $\% \mathrm{FEV}_{1}$ with the family position variable was in agreement with the well-known association of these phenotypes with asthma. ${ }^{1,4,13,33}$ The relationships of these phenotypes with age, gender and smoking habits agreed well with those found in other studies (see Baldacci $e t a l^{28}$ for a review).

The importance of familial determinants underlying the variation of total serum IgE levels is well established. The best fitting pattern of familial correlations for IgE in this EGEA sample could be accounted for by an additive 
Table 3 Maximum likelihood estimates of familial correlations for total lgE levels, sum of positive skin prick tests to allergens (SPTQ) and eosinophil counts (EOS) when adjusting each of these phenotypes for each of the two other ones (first line) and percent reduction in correlations with respect to the estimates obtained from the analysis of the baseline phenotypes (second line $)^{\mathrm{a}}$

\begin{tabular}{|c|c|c|c|c|c|}
\hline Phenotype & $\rho_{F M}(S D)^{b}$ & $\rho_{\text {FO }}(S D)^{b}$ & $\rho_{M O}(S D)^{b}$ & $\rho_{S S}(S D)^{b}$ & $-2 \ln L^{c}$ \\
\hline \multicolumn{6}{|c|}{$\begin{array}{l}\text { Total IgE } \\
\text { Adjusted for SPTQ }\end{array}$} \\
\hline Family set $A$ & $0.04(0.07)$ & $\begin{array}{c}0.19(0.05) \\
9.5 \%\end{array}$ & $0.30(0.05)$ & $\begin{array}{c}0.27(0.06) \\
6.9 \%\end{array}$ & 750.1 \\
\hline Family set B & $0.002(0.10)$ & $\begin{array}{c}0.18(0.08) \\
25.0 \%\end{array}$ & $0.26(0.08)$ & 0.33 (0.09) & 366.1 \\
\hline Family set $A$ & $0.02(0.07)$ & $\begin{array}{c}0.15(0.05) \\
28.6 \%\end{array}$ & $\begin{array}{c}0.27(0.05) \\
10.0 \%\end{array}$ & $0.31(0.06)$ & 757.1 \\
\hline Family set B & $0.05(0.10)$ & $0.24(0.08)$ & $0.26(0.08)$ & $0.31(0.09)$ & 364.0 \\
\hline \multicolumn{6}{|l|}{$\begin{array}{l}\text { SPTQ } \\
\text { Adiusted for laF }\end{array}$} \\
\hline Family set B & $\begin{array}{c}0.04(0.10) \\
-\end{array}$ & $\begin{array}{c}0.16(0.08) \\
15.8 \%\end{array}$ & $\begin{array}{c}0.18(0.09) \\
18.2 \%\end{array}$ & 0.40 (0.09) & 371.6 \\
\hline \multicolumn{6}{|l|}{ EOS } \\
\hline Family set $A$ & $0.05(0.07)$ & $\begin{array}{c}0.09(0.053) \\
30.8 \%\end{array}$ & $\begin{array}{c}0.11(0.05) \\
26.7 \%\end{array}$ & $0.22(0.06)$ & 790.4 \\
\hline Family set B & $\begin{array}{c}0.20(0.10) \\
-\end{array}$ & $\begin{array}{c}0.11(0.082) \\
8.3 \%\end{array}$ & $0.11(0.08)$ & $0.30(0.10)$ & 372.9 \\
\hline
\end{tabular}

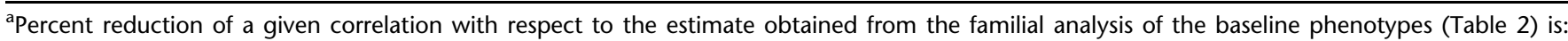
$\left(\left(\rho_{\text {baseline phenotype- }} \rho_{\text {adjusted phenotype }}\right) / \rho_{\text {baseline phenotype }}\right) \times 100$. Results are only shown if a percent reduction in any previously significant familial correlation of at least $10 \%$ was observed. The baseline phenotype is the phenotype adjusted for the relevant variables and the adjusted phenotype is the phenotype adjusted for covariates and one of the others phenotypes.

${ }^{\mathrm{b}} \rho_{\mathrm{FM}}$ : spouse correlation, $\rho_{\mathrm{FO}}$ : father-offspring correlation, $\rho_{\mathrm{MO}}$ : mother-offspring correlation, $\rho_{\mathrm{SS}}$ : sib-sib correlation with standard deviation (SD) in parenthesis; the mean and variance of the phenotypes are not shown (being always close to zero and one).

'In $L$ : natural logarithm of the maximum likelihood.

polygenic model with heritability estimate of $50 \%$ in the total sample and each family set, in agreement with published estimates of heritability ranging from 36 to $61 \%$ (see Los et $a l^{34}$ for a review, ${ }^{35}$ ).

Few studies have estimated the familial correlations of the specific response to allergens. One North-American twin study reported an heritability estimate of $72 \%$ for skin test reactivity, ${ }^{36}$ while, in Australian families from the population, the proportions of variance of a RAST index (measuring specific IgE response) due to additive genetic effects and common sibling environment were 34 and $15 \%{ }^{35}$ These latter estimates were in agreement with our estimates of familial correlations of SPTQ which might be accounted for by additive genetic effects representing 24 and $39 \%$ of total variance in sets A and B, respectively. The excess of $\rho_{\mathrm{SS}}$ with respect to the $\rho_{\mathrm{PO}}$ observed in set $\mathrm{B}$, although not significant, could be explained by a common sibling environment representing $17 \%$ of total variance. Since the distribution of the SPTQ quantitative score departed from normality assumptions, analyses were repeated using different transformations of this score that reduced skewness and kurtosis. Similar parameter estimates using the transformed and untransformed SPTQ were obtained.

Two family studies from the general population in Tucson, Arizona ${ }^{37}$ and Busselton, Australia ${ }^{35}$ found substantial familial correlations for eosinophils. The heritability estimate of $30 \%$ in the Australian sample was consistent with the pattern of correlations observed in set A that could be accounted for by a polygenic model with heritability of $28 \%$. In set $\mathrm{B}$, the only significant $\rho_{\mathrm{SS}}$ estimate of 0.28 was close to that obtained in non-Hispanic white families from Tucson $\left(\rho_{\mathrm{SS}}=0.31\right)$, although the latter sample included also significant mother-offspring correlation. 
The present study showed strong evidence for familial correlations of $\% \mathrm{FEV}_{1}$, as found by most studies. ${ }^{38-41}$ In set A, the pattern of familial correlations was compatible with a polygenic model with heritability of $46 \%$ close to the $39 \%$ estimate in Australian families. ${ }^{41}$ In set B, the significant mother-offspring and sib-sib correlations were in agreement with the patterns of correlations found in American families from the general population or including asthmatics. ${ }^{38,39}$

Although tests of homogeneity of the estimates of familial correlations between set A and set B were never significant, different patterns of correlations were observed in each set for EOS and $\% \mathrm{FEV}_{1}$, confirming the lack of power of these homogeneity tests. Alternatively, the different outcomes of the tests for presence of a given correlation in these two sets should be interpreted in terms of their different sample sizes.

There was strong evidence for individual associations between IgE and SPTQ, IgE and EOS and, in a lesser extent, between EOS and either SPTQ or $\% \mathrm{FEV}_{1}$, in agreement with previous studies in asthmatics and nonasthmatics subjects (see Baldacci et $\mathrm{l}^{28}$ for a review, ${ }^{42}$ ). No association was observed between $\% \mathrm{FEV}_{1}$ and either IgE or SPTQ. Associations between these latter phenotypes have been controversial and appeared to differ according to age, sex, type of allergen considered and smoking status. ${ }^{7,8,43,44}$

Analyses of shared familial determinants among these phenotypes indicated a small overlap of mainly $\rho_{\mathrm{FO}}$ between IgE and SPTQ in the two family sets and of both $\rho_{\mathrm{FO}}$ and $\rho_{\mathrm{MO}}$ between IgE and EOS in family set A, the extent of this overlap being at most $30 \%$. Multivariate linkage and association analyses of these phenotypes with genetic markers will permit to characterize further these common determinants. A similar analysis in randomly selected Australian families showed significant evidence for $70 \%$ overlap of genetic additive variants between IgE and RAST index ${ }^{17}$ while a segregation analysis of IgE and EOS, in the same sample, indicated the presence of two different major genes underlying these phenotypes. ${ }^{18}$ The higher degree of sharing of familial determinants between total IgE and RAST index in the Australian sample than between IgE and SPTQ in the EGEA sample can be first explained by a difference in the phenotypes studied. The RAST index measuring the specific IgE response may be more closely related to total IgE levels than SPTQ, which measures the skin test reactivity to a battery of allergens. Part of the divergence in the results might also be due to the different mode of selection of the two samples, at random for the Australian families and through asthmatics probands in the French sample. Although different analytical methods were used, variance component models in the Australian study and regressive models in the present study, an equivalence between these models has been established when imposing constraints on the more general regressive models, ${ }^{20}$ which can distinguish between father-offspring and mother-offspring correlations. Moreover, because of the complex effects of covariates and associations between phenotypes differing among family members in the present sample, adjustment of each phenotype was carried out prior to familial analysis while the covariate effects were estimated simultaneously with the other parameters of the variance component model in the Australian study.

The decrease in the estimate of $\rho_{\mathrm{FO}}$ when IgE was adjusted for SPTQ and conversely may suggest a parentof-origin effect for this potential common determinant. Indeed, parent-of-origin effects have been reported by previous family studies and linkage analyses of atopyassociated phenotypes (see for example, Moffat and Cookson, Strauch et al and Demenais et $a l^{45-47}$ ). However, the difference in estimates of father-offspring and mother-offspring correlations of IgE adjusted for SPTQ did not reach significance. Further analyses incorporating genetic markers and considering separately paternal and maternal meioses may permit to confirm the present finding.

The independence between the familial determinants of $\% \mathrm{FEV}_{1}$ and those of IgE, SPTQ or EOS suggests the existence of different pathways for atopy-related phenotypes and phenotypes related to ventilatory function. These results are in agreement with the independence of genetic components of variance between airway responsiveness and either IgE levels or RAST index and the absence of common major genes underlying airway responsiveness and either IgE or EOS, as found in two samples of Australian families. ${ }^{17,18}$

In conclusion, the present study confirms the presence of multiple determinants of four important asthmaassociated phenotypes and shows that these determinants are largely unshared by these phenotypes. However, a few of these determinants with modest effects may be common to atopy-related phenotypes. This study has also revealed potential heterogeneity of the mechanisms underlying eosinophils and $\% \mathrm{FEV}_{1}$, according to the mode of ascertainment of the families. All these results have implications for further linkage and association analyses with genetic markers. Considering altogether IgE, SPTQ and EOS in multivariate analyses may lead to identify genes with pleiotropic effects and stratifying the total EGEA sample according to the mode of ascertainment of the families may increase the power to detect the genetic determinants of EOS and $\mathrm{FEV}_{1}$.

EGEA cooperative group: Respiratory epidemiology INSERM U472, Villejuif: I Annesi-Maesano, F Kauffmann (coordinator), MP Oryszczyn. INSERM U408, Paris: M Korobaeff, F Neukirch. Genetics INSERM EMI0006, Evry: F Demenais. INSERM U535, Villejuif: MH Dizier. INSERM U393, Paris: J Feingold. CNG, Evry: M Lathrop. Clinical centers Grenoble: I Pin, C Pison. Lyon: D Ecochard (deceased), F Gormand, Y Pacheco. Marseille: D Charpin, D Vervloet. Montpellier: J Bousquet. Paris Cochin: A 
Lockhart, R Matran (now in Lille). Paris Necker: E Paty, P Scheinmann. Paris Trousseau: A Grimfeld. Data management INSERM ex-U155: J Hochez. INSERM U472: N Le Moual.

\section{Acknowledgements}

This work was partly supported by INSERM-Ministry of Research 'Cohortes et Collections' grant (4CHO6G). We are grateful to INSERM, Université d'Evry and Genopole for their support. We also thank Conseil Régional d'Ile-de-France for contributing to our computer facilities (HHJO1G).

\section{References}

1 Burrows B, Martinez FD, Halonen M, Barbee RA, Cline MG: Association of asthma with serum IgE levels and skin-test reactivity to allergens. $N$ Engl J Med 1989; 320: 271-277.

2 Postma DS, Koppelman GH, Meyers DA: The genetics of atopy and airway hyperresponsiveness. Am J Respir Crit Care Med 2000; 162: S118-S123.

3 Gleich GJ: The eosinophil and bronchial asthma: current understanding. J Allergy Clin Immunol 1990; 85: 422-436.

4 Bousquet J, Chanez P, Vignola AM, Lacoste JY, Michel FB: Eosinophil inflammation in asthma. Am J Respir Crit Care Med 1994; 150: S33-8.

5 Karakoc F, Remes ST, Martinez FD, Wright AL: The association between persistent eosinophilia and asthma in childhood is independent of atopic status. Clin Exp Allergy 2002; 32: 51-56.

6 Sherrill DL, Lebowitz MD, Halonen M, Barbee RA, Burrows B: Longitudinal evaluation of the association between pulmonary function and total serum IgE. Am J Respir Crit Care Med 1995; 152: 98-102.

7 Gottlieb DJ, Sparrow D, O'Connor GT, Weiss ST: Skin test reactivity to common aeroallergens and decline of lung function. The Normative Aging Study. Am J Respir Crit Care Med 1996; 153: 561-566.

8 Sunyer J, Soriano J, Anto JM et al: Sensitization to individual allergens as risk factors for lower FEV1 in young adults. European Community Respiratory Health Survey. Int J Epidemiol 2000; 29: 125-130.

9 Jedrychowski W, Maugeri U, Jedrychowska-Bianchi I, Mroz E: The effect of house dust mite sensitization on lung size and airway caliber in symptomatic and nonsymptomatic preadolescent children: a community-based study in Poland. Environ Health Perspect 2002; 110: 571-574.

10 Kauffmann F, Neukirch F, Korobaeff M, Marne MJ, Claude JR, Lellouch J: Eosinophils, smoking, and lung function. An epidemiologic survey among 912 working men. Am Rev Respir Dis 1986; 134: 1172-1175.

11 Frette C, Annesi I, Korobaeff M, Neukirch F, Dore MF, Kauffmann F: Blood eosinophilia and FEV1. Cross-sectional and longitudinal analyses. Am Rev Respir Dis 1991; 143: 987-992.

12 Mensinga TT, Schouten JP, Weiss ST, Van der Lende R: Relationship of skin test reactivity and eosinophilia to level of pulmonary function in a community-based population study. Am Rev Respir Dis 1992; 146: 638-643.

13 Ulrik CS: Eosinophils and pulmonary function: an epidemiologic study of adolescents and young adults. Ann Allergy Asthma Immunol 1998; 80: 487-493.

14 Cookson W: Genetics and genomics of asthma and allergic diseases. Immunol Rev 2002; 190: 195-206.

15 Allison DB, Thiel B, St Jean P, Elston RC, Infante MC, Schork NJ: Multiple phenotype modeling in gene-mapping studies of quantitative traits: power advantages. Am J Hum Genet 1998; 63: $1190-1201$.
16 Marlow AJ, Fisher SE, Francks C et al: Use of multivariate linkage analysis for dissection of a complex cognitive trait. Am J Hum Genet 2003; 72: 561-570.

17 Palmer LJ, Burton PR, Faux JA, James AL, Musk AW, Cookson WO: Independent inheritance of serum immunoglobulin $\mathrm{E}$ concentrations and airway responsiveness. Am J Respir Crit Care Med 2000; 161: 1836-1843.

18 Palmer LJ, Cookson WO, James AL, Musk AW, Burton PR: Gibbs sampling-based segregation analysis of asthma-associated quantitative traits in a population-based sample of nuclear families. Genet Epidemiol 2001; 20: 356-372.

19 Bonney GE: On the statistical determination of major gene mechanisms in continuous human traits: regressive models. Am J Med Genet 1984; 18: 731-749.

20 Demenais FM, Bonney GE: Equivalence of the mixed and regressive models for genetic analysis. I. Continuous traits. Genet Epidemiol 1989; 6: 597-617.

21 Kauffmann F, Dizier MH, Pin I et al: Epidemiological study of the genetics and environment of asthma, bronchial hyperresponsiveness, and atopy: phenotype issues. Am J Respir Crit Care Med 1997; 156: S123-S129.

22 Kauffmann F, Dizier MH, Annesi-Maesano I et al: Epidemiological study of genetic and environmental factors in asthma, bronchial hyperresponsiveness and atopy. Protocol and potential selection bias. Rev Epidemiol Sante Publique 2001; 49: 343-356.

23 Maccario J, Oryszczyn MP, Charpin D, Kauffmann F: Methodologic aspects of the quantification of skin prick test responses: the EGEA study. J Allergy Clin Immunol 2003; 111: $750-756$.

24 Burney PG, Luczynska C, Chinn S, Jarvis D: The European Community Respiratory Health Survey. Eur Respir J 1994; 7: 954-960.

25 Polgar G, Weng TR: The functional development of the respiratory system from the period of gestation to adulthood. Am Rev Respir Dis 1979; 120: 625-695.

26 Quanjer P: Working party on 'Standardized lung function testing'. Bull Europ Physiopathol Respir 1983; 19: 7-10.

27 Sampogna F, Demenais F, Hochez J et al: Segregation analysis of IgE levels in 335 French families (EGEA) using different strategies to correct for the ascertainment through a correlated trait (asthma). Genet Epidemiol 2000; 18: 128-142.

28 Baldacci S, Omenaas E, Oryszczyn MP: Allergy markers in respiratory epidemiology. Eur Respir J 2001; 17: 773-790.

29 Bonney GE, Lathrop GM, Lalouel JM: Combined linkage and segregation analysis using regressive models. Am J Hum Genet 1988; 43: 29-37.

30 Demenais F, Lathrop M: REGRESS: a computer program incorporating the regressive approach into the LINKAGE programs. Genet Epidemiol 1994; 11: 291.

31 Khoury MJ, Beaty $\mathrm{TH}$, Cohen BH: Fundamentals of genetic epidemiology. Oxford: Oxford University Press, 1993.

32 Clayton D, Hills M: Statistical methods in epidemiology. Oxford: Oxford University Press, 1993.

33 Sears MR, Burrows B, Flannery EM, Herbison GP, Holdaway MD: Atopy in childhood. I. Gender and allergen related risks for development of hay fever and asthma. Clin Exp Allergy 1993; 23: 941-948.

34 Los H, Koppelman GH, Postma DS: The importance of genetic influences in asthma. Eur Respir J 1999; 14: 1210-1227.

35 Palmer LJ, Burton PR, James AL, Musk AW, Cookson WO: Familial aggregation and heritability of asthma-associated quantitative traits in a population-based sample of nuclear families. Eur J Hum Genet 2000; 8: 853-860.

36 Hopp RJ, Bewtra AK, Watt GD, Nair NM, Townley RG: Genetic analysis of allergic disease in twins. J Allergy Clin Immunol 1984; 73: $265-270$.

37 Holberg CJ, Halonen M, Wright AL, Martinez FD: Familial aggregation and segregation analysis of eosinophil levels. Am J Respir Crit Care Med 1999; 160: 1604-1610. 
38 Givelber RJ, Couropmitree NN, Gottlieb DJ et al: Segregation analysis of pulmonary function among families in the Framingham Study. Am J Respir Crit Care Med 1998; 157: $1445-1451$.

39 Holberg CJ, Morgan WJ, Wright AL, Martinez FD: Differences in familial segregation of FEV1 between asthmatic and nonasthmatic families. Role of a maternal component. Am J Respir Crit Care Med 1998; 158: 162-169.

40 Wilk JB, Djousse L, Arnett DK et al: Evidence for major genes influencing pulmonary function in the NHLBI family heart study. Genet Epidemiol 2000; 19: 81-94.

41 Palmer LJ, Knuiman MW, Divitini ML et al: Familial aggregation and heritability of adult lung function: results from the Busselton Health Study. Eur Respir J 2001; 17: 696-702.

42 Sherrill DL, Stein R, Halonen M, Holberg CJ, Wright A, Martinez FD: Total serum IgE and its association with asthma symptoms and allergic sensitization among children. J Allergy Clin Immunol 1999; 104: 28-36.
43 Annesi I, Oryszczyn MP, Frette C, Neukirch F, Orvoen-Frija E, Kauffmann F: Total circulating IgE and FEV1 in adult men. An epidemiologic longitudinal study. Chest 1992; 101: $642-648$.

44 Tracey M, Villar A, Dow L, Coggon D, Lampe FC, Holgate ST: The influence of increased bronchial responsiveness, atopy, and serum IgE on decline in FEV1. A longitudinal study in the elderly. Am J Respir Crit Care Med 1995; 151: 656-662.

45 Moffatt MF, Cookson WO: The genetics of asthma. Maternal effects in atopic disease. Clin Exp Allergy 1998; 28: 56-66.

46 Strauch K, Fimmers R, Kurz T, Deichmann KA, Wienker TF, Baur MP: Parametric and nonparametric multipoint linkage analysis with imprinting and two-locus-trait models: application to mite sensitization. Am J Hum Genet 2000; 66: $1945-1957$.

47 Demenais F, Chaudru V, Martinez M: Detection of parent-oforigin effects for atopy by model-free and model-based linkage analyses. Genet Epidemiol 2001; 21: S186-S191. 